\title{
Identification of hepatic biomarkers for physiological imbalance of dairy cows in early and mid lactation using proteomic technology
}

\author{
K. M. Moyes, ${ }^{1}$ E. Bendixen, M. C. Codrea, and K. L. Ingvartsen ${ }^{2}$ \\ Department of Animal Sciences, Faculty of Science and Technology, Aarhus University, DK-8830 Tjele, Denmark
}

\section{ABSTRACT}

Identification of biomarkers for degree of physiological imbalance (PI), a situation in which physiological parameters deviate from normal, is needed to reduce disease risk and improve production and reproduction performance of cows. The objective was to describe the liver proteome in early and mid lactation for cows with different degrees of PI with a special focus on biomarkers and pathways involved in periparturient disease complexes. Twenty-nine cows in early [49 \pm 22 $\mathrm{d}$ in milk (DIM); $\mathrm{n}=14$ ] and mid (159 \pm 39 DIM; $\mathrm{n}$ $=15)$ lactation were nutrient restricted for $4 \mathrm{~d}$ to increase PI by supplementing the ration with $60 \%$ wheat straw. Liver biopsies were collected -1 and $3 \mathrm{~d}$ relative to restriction. Before restriction, an index for PI was calculated based on plasma nonesterified fatty acids, $\beta$-hydroxybutyrate, and glucose concentrations. Within $\mathrm{E}$ and $\mathrm{M}$ cows, a subsets of 6 cow was classified as having either the greatest (PI) or least (normal; N) degree of PI and were used for isobaric tags for relative and absolute quantitation (iTRAQ)-based quantitative profiling in liver using liquid chromatography-tandem mass spectrometry. We identified pyruvate carboxylase and isocitrate dehydrogenase as potential hepatic biomarkers for PI for cows during early lactation and alcohol dehydrogenase-4 and methylmalonate-semialdehyde dehydrogenase for cows in mid lactation. This preliminary study identified new biomarkers in liver for PI and provided a better understanding of the differences in coping strategies used for cows in PI. Despite the small sample size ( $\mathrm{n}=3 /$ group), the results lay a foundation for future research focused on the usefulness of the hepatic biomarkers for predicting PI and thereby cows at risk for disease during lactation.

Key words: physiological imbalance, liver, biomarker, proteome

Received July 3, 2012.

Accepted January 29, 2013.

${ }^{1}$ Current address: Department of Animal and Avian Sciences, University of Maryland, College Park 20742.

${ }^{2}$ Corresponding author: KlausL.Ingvartsen@agrsci.dk
INTRODUCTION

Despite improvements in genetics and management in the dairy industry over the past decades, the incidence of metabolic diseases (e.g., ketosis and hepatic lipidosis) and reproductive problems is still high (Ingvartsen, 2006). Around parturition, the changing hormonal and metabolic environment, coupled with changes in the nervous, immune, and digestive systems, increase the risk of disease for dairy cows during lactation (Ingvartsen, 2006). The health problems in the dairy industry are associated with reduced animal welfare and economic outcome to the farmer; therefore, the incentive to prevent diseases is strong. As herd size steadily increases, the number of animals that need surveillance per farm staff increases. Consequently, the need exists to develop automated in-line and real-time surveillance systems for use on farm for early detection of at-risk animals based on biomarkers; that is, physiological imbalance (PI). Physiological imbalance has been defined as cows whose physiological parameters deviate from the normal and who consequently have an increased risk of developing production diseases (clinical or subclinical) and reduced production or reproduction (Ingvartsen, 2006). If PI can be prevented through feeding and management, early detection of PI may reduce the risk of certain diseases, particularly in early lactation, as previously proposed (Bjerre-Harpøth et al., 2012; Ingvartsen and Moyes, 2013; Moyes et al., 2013).

Recent evidence suggests that individual concentrations of circulating metabolites, such as NEFA and BHBA, are associated with multiple diseases such as ketosis and displacement of the abomasum (Seifi et al., 2011). Because most diseases in the dairy industry are multi-faceted (Ingvartsen, 2006; Ingvartsen and Moyes, 2013), the use of individual metabolites (e.g., urine or milk BHBA for ketosis, and liver triacylglycerol content for hepatic lipidosis) may not be the optimal method to predict risk of clinical disease in lactating dairy cows. Recent investigations in our laboratory showed that (1) nutrient restriction to experimentally increase PI resulted in marked changes in plasma NEFA, BHBA, and glucose; (2) stage of lactation plays a pivotal role with 
regard to the degree of change in individual metabolites (Bjerre-Harpøth et al., 2012); and (3) an index for PI based on plasma NEFA, BHBA, and glucose was a better indicator for risk of disease in early lactation than calculated energy balance or individual metabolites alone (Moyes et al., 2013). However, it is of major interest to identify alternative biomarkers for PI and for early identification of specific subclinical diseases such as ketosis and hepatic lipidosis.

For the present study, we generated an index for PI based on plasma concentrations of NEFA, BHBA, and glucose, as previously described (Moyes et al., 2013), for cows in early and mid lactation that were subjected to dietary nutrient restriction to experimentally increase PI (Bjerre-Harpøth et al., 2012) and thus to understand the biological basis for PI that will help reduce risk of production diseases such as fatty liver and ketosis. The isobaric tags for relative and absolute quantitation (iTRAQ) method (Gygi et al., 1999; Ross et al., 2004), when combined with mass spectrometry, is ideally suited for the identification of biomarkers via its comparative and quantitative multiplexing analysis (Song et al., 2008). For this study, liver samples from a subset of cows with the greatest (i.e., PI) and least (i.e., normal) degree of PI were compared by iTRAQ-based proteomic profiling. Our objectives were to describe the liver proteome in early and mid lactation for cows at different degrees of PI with a special focus on biomarkers and pathways involved in periparturient disease complexes. This study identifies preliminary biomarkers for cows in early and mid lactation and describes changes in relevant pathways during a nutrient restriction period. The results lay a foundation for future studies examining the usefulness of the biomarkers as predictors of PI that provide a better understanding of the biological bases for PI and risk of disease for cows during lactation.

\section{MATERIALS AND METHODS}

All procedures involving animals were evaluated and approved by the Danish Animal Experiments Inspectorate and complied with the Danish Laws concerning animal experimentation and care of experimental animals.

\section{Animals and Housing}

Data for this study originated from a larger experiment that included 47 healthy Holstein cows from the resident herd (Danish Cattle Research Centre, Tjele, Denmark). Descriptions of experimental design, diet composition, and data collection may be found in a previous publication (Bjerre-Harpøth et al., 2012). In short, a subset of 29 cows in early $(49 \pm 22$ DIM; $\mathrm{n}=$ 14) and mid (159 \pm 39 DIM; $\mathrm{n}=15)$ lactation were selected to identify biomarkers for PI. Of these, 13 cows were primiparous and 16 cows were multiparous $(\geq 2$ second lactation). Cows in early lactation had an average milk yield of $42.0 \pm 7.0 \mathrm{~kg} / \mathrm{d}$ and weighed $647 \pm 58$ $\mathrm{kg}$; cows in mid lactation had an average milk yield of $29.0 \pm 7.3 \mathrm{~kg} / \mathrm{d}$ and weighed $623 \pm 57 \mathrm{~kg}$ at the start of the study.

Cows were housed in a single group in a loose housing system containing individual automatic feeding stations (Roughage Intake System, Insentec BV, Marknesse, the Netherlands) and milked automatically by an automatic milking system (VMS, Voluntary Milking System, DeLaval, Tumba, Sweden). Freestalls contained mats of hard rubber material and sawdust as bedding. Cows had free access to water and the VMS at all times throughout the study period. Cows were weighed automatically at each milking via an electronic scale placed in the VMS and average daily BW was calculated.

\section{Experimental Design and Diets}

The 19-d experiment consisted of 3 periods (i.e., 1 $=$ before restriction, $2=$ during restriction, and $3=$ recovery). Period 1 was an 8 -d control period where feed intake, BW, daily milk production, and milk composition were measured. During period 1 (i.e., -120 to $0 \mathrm{~h}$ relative to nutrient restriction), all cows were fed the same standard control diet and were allowed $3 \mathrm{~kg} / \mathrm{d}$ of VMS concentrates (Bjerre-Harpøth et al., 2012). During period 2 (0-96 h relative to nutrient restriction; $4 \mathrm{~d}$ ), dietary intake for all cows was restricted to provide $\sim 40 \%$ of requirements recommended by the NRC (2001) for $\mathrm{NE}_{\mathrm{L}}$ based on BW, milk production, and milk composition by substituting $60 \%$ of the control TMR with wheat straw. This feeding strategy was designed to allow for ad libitum intake and maintain gut fill while limiting nutrient intake. To avoid negative effects due to limited protein supply, the mix was adjusted to maintain a dietary protein content of $12 \%$. To prevent separation of the straw and control TMR, 300 $\mathrm{mL}$ of water $/ \mathrm{kg}$ of feed was added during mixing. During nutrient restriction, cows were allowed only $300 \mathrm{~g}$ of concentrates per visit in the VMS, with a maximum intake of $1.0 \mathrm{~kg} / \mathrm{d}$. During period 3, cows returned to the control diet and were monitored for an additional 7 d (i.e., recovery period; $97-264 \mathrm{~h}$ relative to restriction). Energy balance was calculated according to NRC recommendations, as described by Bjerre-Harpøth et al. (2012). 


\section{Sampling and Analysis}

Plasma. Blood samples were collected in the mornings $(\sim 0900 \mathrm{~h})$ at $-96,-48,24,48,72,96,120,144$, 216 , and $264 \mathrm{~h}$ relative to the start of restriction by puncture of the coccygeal vein or artery using Vacutainer tubes containing sodium heparin (BD Vacutainer Systems, Plymouth, UK). Plasma was harvested following centrifugation at $2,000 \times g$ for $20 \mathrm{~min}$ at $4^{\circ} \mathrm{C}$ and stored at $-18^{\circ} \mathrm{C}$ until further analysis. Plasma was analyzed for glucose, NEFA, phospholipids, cholesterol, total bile acids, haptoglobin, BHBA, triacylglycerol (TAG), total protein, aspartate transferase, BUN, albumin, alkaline phosphatase, and $\gamma$-glutamyl transferase using an autoanalyzer (ADVIA 1650 Chemistry System, Siemens Medical Solution, Tarrytown, NY) according to methods described by Bjerre-Harpøth et al. (2012). Plasma insulin was analyzed via time-resolved fluoro-immunometric assay (Perkin Elmer, Skovlunde, Denmark) using a bovine insulin standard, as described by Løvendahl and Purup (2002).

Milk. At each milking from -120 through $240 \mathrm{~h}$ relative to nutrient restriction, milk yield was recorded and composite milk samples were collected. Details on analyses are reported elsewhere (Bjerre-Harpøth et al., 2012). Briefly, composite milk samples collected were analyzed for fat $(\%)$, protein $(\%)$, lactose $(\%)$, citric acid $(\mathrm{m} M)$, and SCC (cells $/ \mathrm{mL}$ ) using a CombiFoss 4000 (Foss Electric A/S, Hillerød, Denmark). A subset of composite milk samples collected between $1630 \mathrm{~h}$ to $600 \mathrm{~h}$ were analyzed for BHBA, MUN, and alkaline phosphatase activity.

Liver. Liver biopsies were collected in the mornings $(\sim 0900 \mathrm{~h})$ at -48 and $72 \mathrm{~h}$ relative to the start of restriction. Tissue was frozen immediately in liquid N, transferred to a $-80^{\circ} \mathrm{C}$ freezer for storage, and later analyzed for contents of phospholipid, glucose, glycogen, and TAG, as previously described (Bjerre-Harpøth et al., 2012).

\section{PI Index}

The PI index was calculated as described by Moyes et al. (2013) for each individual cow using average plasma NEFA, BHBA, and glucose concentrations from period 1 only (i.e., before restriction). Metabolites were weighted equally and the equation was as follows: PI index $=[\ln (\mathrm{NEFA})]+[\ln (\mathrm{BHBA})]-[$ glucose $]$. The index generated the top 3 cows ( 6 in total) with the greatest (i.e., PI) and least (normal; N) degree of PI within each group.

\section{Sample Preparation}

In addition to the 24 liver samples selected for iTRAQ-based quantification, a common reference sample was created by pooling equal aliquots of liver tissue from 12 randomly chosen cows from previous experiments at $1,3,4$, and $6 \mathrm{wk}$ in lactation $(\mathrm{n}=3$ / week of lactation). Although this type of pooled reference reduces the amplitude of differential expression ratios (i.e., lower fold changes), it allows for comparison across multiple iTRAQ runs from several different experiments to ensure that the reference channel used contains all proteins needed for quantification. The pooled reference sample will be used in future studies to examine the relevance of the biomarker(s) for PI across different breeds, parities, and dietary treatments. This reference sample was divided into 10 identical replicates (50 $\mu \mathrm{L}$ total volume), with 1 aliquot sufficient for 4 iTRAQ runs. The 32 samples (i.e., 24 experimental +8 reference) were treated in parallel through sample preparation and labeling of peptides with iTRAQ. The protein content in each sample was precipitated by adding 6 volumes of ice-cold acetone (1:6). Stock reagents, buffers, and the 4 isobaric tagging reagents were obtained from the iTRAQ Reagent Multiplex kit (Applied Biosystems, Foster City, CA), and labeling was performed according to the manufacturer's manual (Ross et al., 2004).

In brief, the precipitated protein $(120 \mu \mathrm{g})$ was resuspended in $20 \mu \mathrm{L}$ of digestion buffer $(0.5 \mathrm{M}$ triethylammonium bicarbonate, $0.1 \%$ SDS). Cysteine residues were reduced with $2.5 \mathrm{mM}$ Tris(2-carboxyethyl)phosphine $\left(60^{\circ} \mathrm{C}\right.$ for $\left.1 \mathrm{~h}\right)$ and then blocked with $10 \mathrm{mM}$ methyl methanethiosulfate at room temperature for 10 min. The proteins were digested with trypsin by adding $10 \mu \mathrm{L}$ of $1 \mu \mathrm{g} / \mathrm{mL}$ stock solution (Applied Biosystems, cat. no. 4352157) and incubated at $37^{\circ} \mathrm{C}$ overnight. Each sample was passed through a $0.2-\mu \mathrm{m}$ centrifuge filter (National Scientific Company, Rockwood, TN) for 5 min at $5,000 \times g$ to remove all the impurities that could interfere with later HPLC separation. Isobaric tagging iTRAQ reagent ( 1 unit in ethanol) was added directly to the protein digests and incubated at room temperature for $1 \mathrm{~h}$.

\section{iTRAQ-Labeling Designs}

The 32 samples were labeled and combined in 1:1:1:1 ratios into 4-plexed samples, each containing a common reference sample and 3 experimental samples (Table 1 ). The common reference sample was labeled with iTRAQ reagent 114, and was included in all 8 iTRAQ experiments. After labeling, the 4-plexed samples were dried by vacuum and stored at $-80^{\circ} \mathrm{C}$.

\section{Strong Cation Exchange Fractionation}

The peptides were redissolved in $0.03 \%$ formic acid (MA), 5\% acetonitrile (ACN)-water. Peptide mix- 
Table 1. The isobaric tags for relative and absolute quantitation (iTRAQ) labeling scheme for liver samples collected at -24 and $72 \mathrm{~h}$ relative to feed restriction (i.e., 0-96 h) from cows in early and mid lactation classified based on degree of physiological imbalance $(\mathrm{PI})^{1}$

\begin{tabular}{|c|c|c|c|c|}
\hline \multirow[b]{2}{*}{ iTRAQ } & \multicolumn{4}{|c|}{ iTRAQ labeling and reporter ions $^{2}$} \\
\hline & 114 & 115 & 116 & 117 \\
\hline 1 & Ref. $^{3}$ & 1, early, N, -24 & 1, early, N, 72 & 2, early, PI, -24 \\
\hline 2 & Ref. & 2 , early, PI, 72 & 3 , early, N, -24 & 3, early, N, 72 \\
\hline 3 & Ref. & 4, early, PI, -24 & 4, early, PI, 72 & 5, early, N, -24 \\
\hline 4 & Ref. & 5 , early, N, 72 & 6, early, PI, -24 & 6, early, PI, 72 \\
\hline 5 & Ref. & 7, mid, $\mathrm{N},-24$ & 7 , mid, $N, 72$ & 8, mid, PI, -24 \\
\hline 6 & Ref. & 8, mid, PI, 72 & 9, mid, $\mathrm{N},-24$ & 9, mid, $N, 72$ \\
\hline 7 & Ref. & 10, mid, PI, -24 & 10, mid, PI, 72 & 11, mid, $\mathrm{N},-24$ \\
\hline 8 & Ref. & $11, \operatorname{mid}, \mathrm{N}, 72$ & 12, mid, PI, -24 & 12, mid, PI, 72 \\
\hline \multicolumn{5}{|c|}{$\begin{array}{l}{ }^{1} \text { The PI index }=\ln [\mathrm{NEFA}]_{\text {plasma }}+\ln [\mathrm{BHBA}]_{\text {plasma }}-[\text { glucose }]_{\text {plasma }} \text {. For each cow, the PI index was calculated } \\
\text { based on averages before feed restriction. The top } 3 \text { cows classified as having the least (normal, N; } \mathrm{n}=3 \text { ) or } \\
\text { greatest }(\mathrm{PI} ; \mathrm{n}=3 \text { ) degree of PI were used. }\end{array}$} \\
\hline \multicolumn{5}{|c|}{$\begin{array}{l}\left.{ }^{2} \text { Scheme for reporter ions } 115,116 \text {, and } 117 \text { : cow number ( } 1 \text { to } 12\right) \text {, stage of lactation (early or mid), PI clas- } \\
\text { sification }[\text { normal }(\mathrm{N}) \text { or PI], and time (h) relative to nutrient restriction for collection of liver tissue. }\end{array}$} \\
\hline \multicolumn{5}{|c|}{$\begin{array}{l}{ }^{3} \text { Common reference sample was made from equal amounts of liver tissue randomly collected from } 12 \text { cows from } \\
\text { previous experiments ranging from } 1 \text { to } 6 \text { wk in lactation. }\end{array}$} \\
\hline
\end{tabular}

tures generated from digestion of $50 \mu \mathrm{g}$ of protein were injected into an Agilent 1100 Series capillary HPLC equipped with a Zorbax Bio-SCX Series II, $0.8 \times 50 \mathrm{~mm}$ column (Agilent Technologies, Palo Alto, CA). Buffer A contained $0.03 \% \mathrm{MA}$ and $5 \% \mathrm{ACN}$-water, buffer B contained $0.03 \% \mathrm{MA}, 5 \% \mathrm{ACN}$-water, and $1 \mathrm{M} \mathrm{NaCl}$ in water, and the flow rate was $15 \mu \mathrm{L} / \mathrm{min}$. Peptides were eluted with a gradient of increasing $\mathrm{NaCl}(0 \mathrm{~min}, 0 \%$ $\mathrm{B} ; 5 \mathrm{~min}, 0 \% \mathrm{~B} ; 10 \mathrm{~min}, 1.5 \% \mathrm{~B} ; 11 \min 4 \% \mathrm{~B} ; 25.5$ min, $15 \% \mathrm{~B}$; $35.5 \mathrm{~min}, 50 \% \mathrm{~B} ; 45 \mathrm{~min}, 100 \% \mathrm{~B}$; and 55 min, $100 \%$ B). Fractions were collected every 1 min for $60 \mathrm{~min}$. The strong cation exchange (SCX) fractions were selected and pooled into 10 samples for liquid chromatography-tandem mass spectrometry (LC-MS / MS) analyses.

\section{LC-MS/MS}

The SCX fractions were further separated on an Agilent 1100 Series nanoflow HPLC system (Agilent Technologies) before mass spectrometric identification. Samples were loaded with an isocratic pump in $(0.1 \%$ $\mathrm{MA}$ and $3 \% \mathrm{ACN}$-water) to an enrichment column (Zorbax 300SB C18, $0.3 \times 5 \mathrm{~mm}, 5-\mu \mathrm{m}$ particle, Agilent Technologies) at $20 \mu \mathrm{L} / \mathrm{min}$ to ensure sample desalting and concentration. The enrichment column was then switched into the nanoflow path $(300 \mathrm{~nL} / \mathrm{min})$, and the peptides were eluted and further separated on an analytical column (Zorbax 300SB C18, $75 \mu \mathrm{m} \times 150$ $\mathrm{mm}, 3.5-\mu \mathrm{m}$ particle) using a gradient with increasing organic solvent (0 min, 5\% B; $7 \mathrm{~min}, 5 \% \mathrm{~B} ; 70 \mathrm{~min}$, $40 \%$ B; 73 min, $95 \%$ B; 78 min, $95 \%$ B; 83 min, $5 \%$ $\mathrm{B}$; and $100 \mathrm{~min}, 5 \% \mathrm{~B}$ ). Buffer A contained 0.1\% MA in water and buffer $\mathrm{B}$ contained $5 \%$ water and $0.1 \%$ MA in ACN-water. The eluted peptides were sprayed through a nanospray needle (New Objective, PicoTip Emitter, SilicaTip, no coating, o.d. $360 \mu \mathrm{m}$, i.d. $20 \mu \mathrm{m}$ ) directly into the Q-star Elite mass spectrometer (Applied Biosystems).

\section{Database Searching and Data Analysis}

The raw data files were processed with the ProteinPilot 1.0 software (Applied Biosystems) using the ProGroup and Paragon algorithms for protein grouping and confidence scoring. The target database used for searching was constructed as a nonredundant union of bovine sequences from UniProtKB (http://www. uniprot.org/taxonomy/9913), UniGene (http://www. ncbi.nlm.nih.gov/UniGene/UGOrg.cgi?TAXID=9913), and Ensembl (http://www.ensembl.org/Bos_taurus/ Info/Index; May 2010) plus common contaminants (the collected search database is available upon request from the authors). A similar number of reversed sequences was appended to the target protein list. The raw data files were not preprocessed (e.g., smoothed) before database searching. The database used the generic modification set, which included, among others, deamidation and methionine oxidation. In addition, identification of (methyl methanethiosulfate) cysteine was allowed. Search parameters within the ProteinPilot were set with an MS tolerance of $0.15 \mathrm{Da}$ and an MS/MS tolerance of 0.1 Da. Each sample was SCX-fractionated and analyzed twice to gain higher reproducibility and proteome coverage, as recommended by Chong et al. (2006). The 2 data files from each sample were searched 
together in ProteinPilot. Confidence of protein identification was selected in ProteinPilot to ProtScore of 1.3 (equivalent to $95 \%$ confidence) and a minimum of 2 peptides per protein. The 8 individual results files were merged and aligned using accession numbers.

\section{Statistical Analysis}

Statistical analysis of the liver proteome data was carried out using the standard repeated one-way ANOVA procedure in $\mathrm{R}$ ( $\mathrm{R}$ Development Core Team, http:// www.R-project.org). Preliminary results showed no biomarkers were similar between PI cows in early and mid lactation, and therefore, the model was analyzed separately for cows in early and mid lactation. Fold change was presented as the ratio of the least squares means for normalized expression values of PI versus $\mathrm{N}$ cows.

For the selected subset of 12 cows in either early or mid lactation, the MIXED procedure of SAS (version 9.2; SAS Institute, 2008) with the repeated measure of hours relative to start of restriction $(\mathrm{h}=0)$ was used to characterize the effect of PI and dietary challenge on changes in milk, plasma, and liver components. Data collected from -96 (i.e., time of blood sampling) through $96 \mathrm{~h}$ (i.e., end of the restriction period) relative to restriction were used for statistical analysis. The model was analyzed separately for cows in early and mid lactation. All blood and liver parameters, except plasma glucose, albumin, phospholipids, and plasma urea $\mathrm{N}$, were natural $\log (\mathrm{ln})$ transformed, and the natural log of milk SCC were used for statistical analysis. The random effect of cow was used as the error term in the REPEATED statement with auto-regressive (1) as the covariance structure. The class variables included cow, degree of PI, and $h$ relative to feed restriction with model $\mathrm{Y}_{i j k}=\mu+\mathrm{PI}_{k}+\mathrm{H}_{j}+\mathrm{P}_{k} \times \mathrm{H}_{j}+\mathrm{C}_{i}+$ $\mathrm{e}_{i j k}$, where $\mathrm{Y}_{i j k}=$ dependent variable at hour $j(j=$ $-72,-48,-24,24,48$, and 72 ) for the ith cow within the $k$ th degree of PI $(k=\mathrm{PI}$ or $\mathrm{N}) ; \mu=$ overall mean; $\mathrm{PI}_{k}=$ the fixed effect of PI; $\mathrm{H}_{j}=$ the fixed effect of $\mathrm{h}$ relative to restriction; $\mathrm{PI}_{k} \times \mathrm{H}_{j}=$ the interaction of $\mathrm{PI}$ and hours relative to restriction; $\mathrm{C}_{i}=$ the random effect of cow $i$; and $\mathrm{e}_{i j k}=$ the experimental error. Degrees of freedom were estimated with the Kenward-Roger specification in the model statements. Data are presented as least squares means plus standard errors of the mean $(\mathrm{LSM} \pm \mathrm{SEM})$. Separation of LSM for significant effects was accomplished using the Tukey option within the MIXED procedure of SAS (SAS Institute, 2008). The LSM and SEM for all natural log-transformed data were back-transformed (geometric mean) for presentation of results.

\section{RESULTS}

\section{Differences in Metabolite, Hormone, and Enzyme Concentration in Blood, Milk, and Liver by PI}

For cows in early and mid lactation, daily milk yield and DMI did not differ between PI and N cows before feed restriction (Table 2). Figure 1 shows the differences in concentration of plasma glucose (A), plasma NEFA (B), plasma BHBA (C), daily milk yield (D), milk BHBA $(\mathrm{E})$, calculated energy balance $(\mathrm{F})$, liver TAG $(\mathrm{G})$, and liver glycogen $(\mathrm{H})$ at time points relative to nutrient restriction for cows in early and mid lactation classified by degree of PI (i.e., PI or N). Regardless of degree of PI, plasma glucose decreased $(P<0.001)$ for all cows during restriction. For cows in early lactation, plasma glucose was lower $(P=0.01)$ for PI $(3.61$ $\pm 0.1 \mathrm{~m} M)$ than $\mathrm{N}(2.98 \pm 0.1 \mathrm{~m} M)$ cows throughout the study period. This was supported by the lower $(P$ $=0.05)$ plasma insulin concentration observed for PI compared with $\mathrm{N}$ cows in early lactation (data not shown). For cows in mid lactation, PI did not correlate $(P=0.88)$ with changes in plasma glucose or insulin. Before restriction, plasma NEFA was higher $(P<0.05)$ for PI $(1,203 \pm 114 \mathrm{mEq} / \mathrm{L})$ than for $\mathrm{N}(697.0 \pm 66$ $\mathrm{mEq} / \mathrm{L}$ ) cows in early lactation, whereas no differences were observed between PI and $\mathrm{N}$ cows in mid lactation. During restriction, plasma NEFA increased for all groups and no differences were observed between PI and N cows, regardless of stage of lactation. During restriction, plasma and milk BHBA concentration increased for PI when compared with $\mathrm{N}$ cows in early lactation. For cows in mid lactation, PI cows had higher overall milk BHBA concentration $(P<0.01)$ than $\mathrm{N}$ cows throughout the study period. Overall total plasma protein was higher $(P<0.01)$ for PI compared with $\mathrm{N}$ cows in mid lactation, whereas no differences were observed for cows in early lactation (data not shown). Daily milk yield decreased during restriction for all cows $(P<0.01)$ and did not differ by degree of PI, regardless of stage of lactation. Milk citric acid tended to be $(P$ $<0.10)$ and protein was $(P<0.05)$ significantly higher for PI compared with $\mathrm{N}$ cows in mid lactation, whereas milk fat was higher $(P<0.05)$ in PI compared with $\mathrm{N}$ cows in mid lactation only (data not shown). For cows in early and mid lactation, calculated energy balance was lower $(P=0.05$; Figure $1 \mathrm{~F})$ for PI compared with $\mathrm{N}$ cows throughout the study period. No other variables in plasma, milk, or liver differed between PI and N cows in early and mid lactation. For cows in early lactation, liver TAG was higher $(P<0.05)$ for PI $(11.0 \pm$ $1.8 \%$ of wet weight) compared with $\mathrm{N}(4.4 \pm 1.8 \%$ of wet weight) cows throughout the study period, whereas liver glycogen tended to be lower $(P<0.10)$ for PI 
Table 2. Means ( \pm SD) for the physiological imbalance (PI) index, DIM, daily milk yield, and DMI for cows (n $=3$ /group) used to identify biomarkers for PI via isobaric tags for relative and absolute quantitation (iTRAQ)based quantitative profiling in liver using liquid chromatography-tandem mass spectrometry

\begin{tabular}{lrccc}
\hline $\begin{array}{l}\text { Stage of lactation } \\
\text { and PI category }\end{array}$ & PI index & & \\
& & DIM $^{2}$ & Milk yield, kg & DMI, kg \\
\hline Early & & & & \\
PI $^{3}$ & $0.58 \pm 0.26$ & $30.7 \pm 12.5$ & $41.0 \pm 6.3$ & $20.5 \pm 4.2$ \\
$\mathrm{~N}^{3}$ & $-0.16 \pm 0.16$ & $51.7 \pm 3.1$ & $38.7 \pm 7.9$ & $20.5 \pm 3.4$ \\
Mid & & & $30.8 \pm 2.8$ & $21.3 \pm 1.5$ \\
PI & $-0.10 \pm 0.48$ & $135 \pm 38$ & $27.7 \pm 8.9$ & $19.8 \pm 1.6$ \\
N & $-0.60 \pm 0.66$ & $137 \pm 39$ & \\
\hline
\end{tabular}

${ }^{1}$ The PI index was generated from a subset of cows from a previous study in early $(\mathrm{n}=14 ; 22-86$ DIM) and mid $(\mathrm{n}=15 ; 100-217 \mathrm{DIM})$ lactation, where PI index $=\ln [\mathrm{NEFA}]_{\text {plasma }}+\ln [\mathrm{BHBA}]_{\text {plasma }}-[\text { glucose }]_{\text {plasma }}$. For each cow, the PI index was calculated based on averages before nutrient restriction. The PI index is expressed in relative units.

${ }^{2}$ DIM before nutrient restriction.

${ }^{3}$ The PI index generated the top 3 cows with the greatest (i.e., PI) and least (i.e., normal; N) degree of PI within early and mid lactation.

compared with $\mathrm{N}$ cows before restriction (Figures $1 \mathrm{G}$ and $H$, respectively). Nutrient restriction resulted in higher liver TAG and lower glycogen content, regardless of stage of lactation and degree of PI. Liver TAG and glycogen content were similar between PI and N cows in mid lactation throughout the study period. Liver phospholipid was not altered by PI throughout the study period for cows in early and mid lactation. Liver glucose content tended $(P=0.06)$ to be lower for PI compared with $\mathrm{N}$ cows in mid lactation only (data not shown).

\section{Protein Identification and Coverage}

The 8 iTRAQ runs were searched individually and provided, on average, $410 \pm 37$ protein groups identified at $95 \%$ confidence. By merging and aligning the individual results, 704 distinct protein groups were found. Of these, 169 proteins were identified in a single run ("one-hit wonders") and 213 were identified in all 8 runs. The complete histogram of the protein hits with respect to the number of runs was $169,67,68,54,49$, 33 , 51, and 213 for runs 1 to 8 , respectively. The subsequent statistical analysis was performed on the 213 proteins shared among the 8 runs that contained all the necessary samples. Three reversed sequences were observed in 3 individual files and none was observed more than once. Therefore, the false discovery rate of protein identification was virtually zero for the 213 proteins common to the 8 runs.

\section{Liver Proteome for Cows in Early Lactation at Different Degrees of PI}

Table 3 shows the significantly $(P \leq 0.05)$ up- or downregulated proteins in liver by PI before and dur- ing restriction for cows in early lactation. Physiological imbalance resulted in a total of 5 proteins being differentially expressed between PI and N cows. Two proteins were upregulated by PI: pyruvate carboxylase (PC; 1.2-fold change), an enzyme involved in gluconeogenesis; and very long chain specific acyl-CoA dehydrogenase (VLCAD; 1.15-fold change), an enzyme involved in $\beta$-oxidation of long-chain fatty acids. Three proteins were downregulated by PI, all of which are involved in energy metabolism: mitochondrial isocitrate NADP+dependent dehydrogenase (ICDHm; -1.24-fold change); xenobiotic detoxification (glycine N-acyltransferase, GLYAT; -1.2-fold change); and UDP-glucose 6-dehydrogenase (UGDH; -1.06-fold change).

During nutrient restriction to experimentally increase PI, 11 proteins were differentially expressed between $\mathrm{PI}$ and $\mathrm{N}$ cows, of which 5 were upregulated. These included proteins involved in $\beta$-oxidation of long-chain fatty acids [mitochondrial trifunctional protein, subunit $\alpha$ (MTP- $\alpha$; 1.22-fold change); enoyl-coenzyme A hydratase (ECH; 1.13-fold change)] and gluconeogenesis (PC; 1.14-fold change). Six proteins were downregulated, including proteins related to antioxidant defense glutathione S-transferase Mu 1 (GSTM-1; -1.46-fold change), manganous superoxide dismutase (MnSOD; -1.22-fold change), aldehyde oxidase (AOX; -1.19-fold change), and GLYAT (-1.25-fold change), apoptosis (14-3-3 protein $\beta / \alpha ;-1.24$-fold change), and fatty acid binding (liver fatty acid binding protein; L-FABP; -1.14-fold change).

\section{Liver Proteome for Cows in Mid Lactation at Different Degrees of PI}

For cows in mid lactation, the differential expression of proteins by PI before and during nutrient restriction 

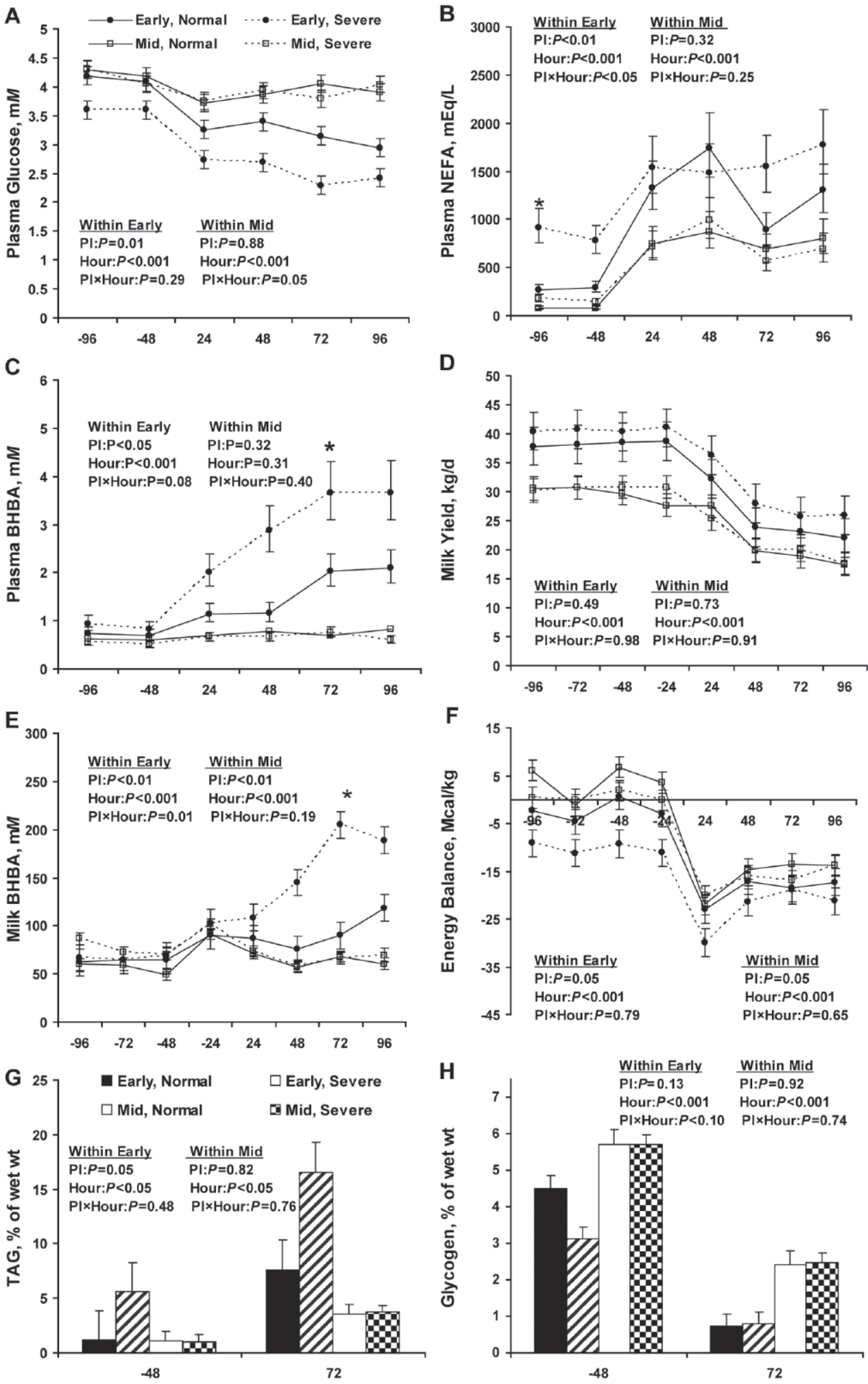

Hour Relative to Nutrient Restiction $(0-96$ h)

Hour Relative to Nutrient Restiction (0-96 h)

Figure 1. Differences in concentrations of (A) plasma glucose, (B) plasma NEFA, (C) plasma BHBA, (D) daily milk yield, (E) milk BHBA, (F) calculated energy balance (NRC, 2001); (G) liver triacylglycerol (TAG), and (H) liver glycogen at time points relative to nutrient restriction $(0$ h) from 12 Holstein cows in early $(\bullet)$ and mid $(\square)$ lactation classified as having either the least (normal, N; solid lines) or greatest (PI; severe; dashed lines) degree of physiological imbalance (PI). *Differences $(P<0.05)$ between $\mathrm{N}$ and PI cows in early lactation at any given time point. For cows in mid lactation, no differences $(P>0.05)$ were observed between $\mathrm{N}$ and PI cows at any given time point. 
Table 3. Significantly $(P \leq 0.05)$ up- or downregulated proteins before and during nutrient restriction for cows in early lactation classified based on degree of physiological imbalance $(\mathrm{PI})^{1}$

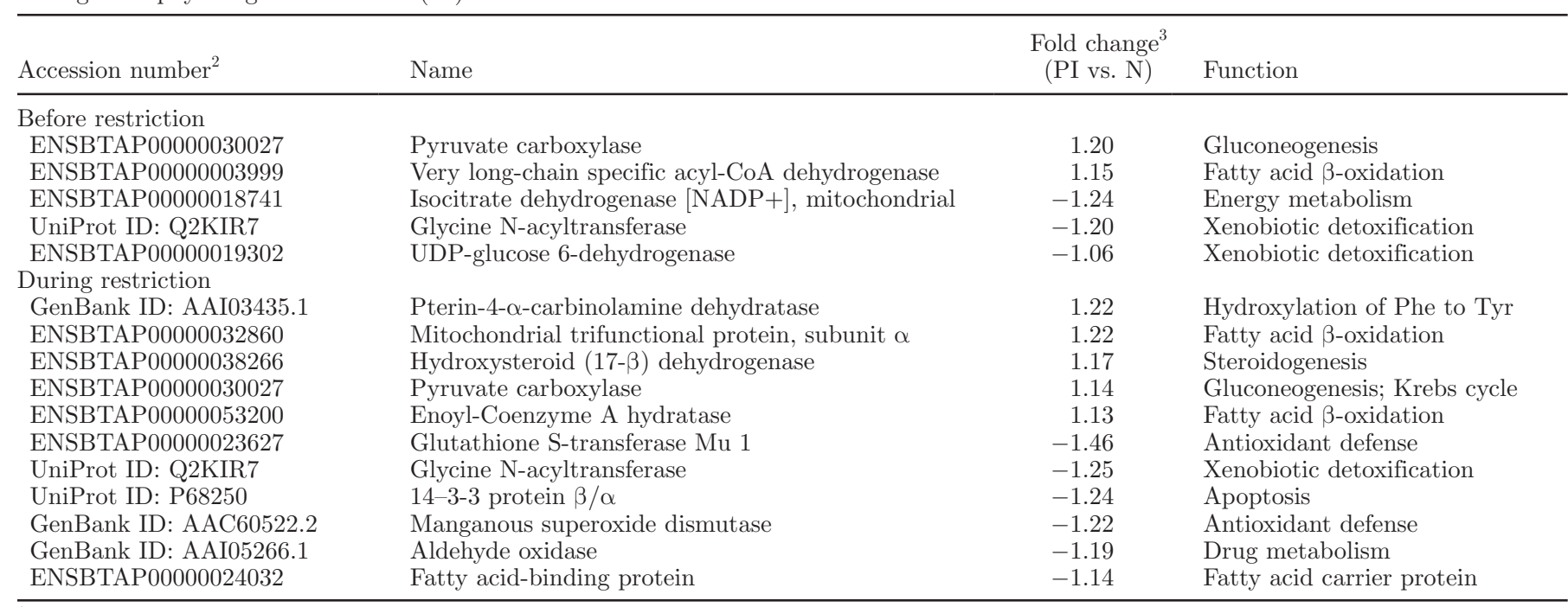

${ }^{1}$ The PI index was generated from a subset of 6 Holstein cows, where PI index $=\ln [\mathrm{NEFA}]_{\text {plasma }}+\ln [\mathrm{BHBA}]_{\text {plasma }}-[\text { glucose }]_{\text {plasma. }}$ For each cow, the PI index was calculated based on averages before nutrient restriction. The top 3 cows classified as having the least (normal, $\mathrm{N}$; $\mathrm{n}=3$ ) or greatest $(\mathrm{PI} ; \mathrm{n}=3)$ degree of PI were used.

${ }^{2}$ Databases used: UniProtKB (http://www.uniprot.org/taxonomy/9913), UniGene (http://www.ncbi.nlm.nih.gov/UniGene/UGOrg. cgi?TAXID=9913), and Ensembl (http://www.ensembl.org/Bos_taurus/Info/Index).

${ }^{3}$ Fold-change difference in expression of liver proteins for cows classified as PI versus N.

is shown in Table 4. Before restriction, 8 proteins were differentially expressed by PI. Six were upregulated by PI, including proteins involved in ketone biosynthesis [alcohol dehydrogenase 4 (ADH-4; 1.2-fold change); and alcohol dehydrogenase [NADP+] $(\mathrm{ADH}[\mathrm{NADP}+]$; 1.07-fold change)] and the tricarboxylic acid cycle [dihydrolipoamide dehydrogenase 2 (DLD; 1.12 -fold change) and methylmalonate-semialdehyde dehydrogenase (MMSDH; 1.06-fold change)]. Downregulated proteins were primarily involved in antioxidant defense and $\mathrm{CO}_{2}$ transport [carbonic anhydrase 3 (CAR-3; -1.14-fold change)].

Nutrient restriction to experimentally increase PI resulted in 15 differentially expressed proteins, of which 7 were up- and 8 were downregulated between PI and $\mathrm{N}$ cows. Of the proteins upregulated, the majority (n $=4$ ) were associated with fatty acid oxidation such as acetyl-coenzyme A oxidase 2 (ACO-2; 1.14-fold change), acyl-CoA-binding protein (ACBP; 1.10-fold change), and carnitine O-palmitoyltransferase 2 (CPT$2 ; 1.09$-fold change). Acetyl-coenzyme A acyltransferase 1 [thiolase II (Thl-2); 1.14-fold change] is involved in ketone biosynthesis. Experimentally increasing PI resulted in a downregulation of proteins involved in antioxidant defense [peptide methionine sulfoxide reductase (PMSR; -1.23 -fold change), GSTA-1 (-1.22-fold change), and CAR-3 (-1.19-fold change)], amino acid metabolism (PMSR and ornithine carbamoyltransferase; OTC; -1.10 -fold change), and fatty acid oxidation [short-chain specific acyl-CoA dehydrogenase (SCAD; -1.05-fold change); hydroxyacyl-coenzyme A dehydrogenase (HADH; -1.07-fold change)].

\section{DISCUSSION}

Major changes in the endocrine, immune, and digestive systems, for example, occur around parturition and play vital roles in the transition from pregnancy to lactation (Ingvartsen, 2006). Deviations from normal for any of these physiological systems increases degree of PI and thereby risk of disease, especially during early lactation (Ingvartsen and Moyes, 2013). Biomarkers that accurately reflect changes in the endocrine, immune, and digestive systems, and thereby degree of PI, during lactation are lacking. We have previously generated an index for PI, based on metabolites in blood, that more directly relates to the development of disease during early lactation than calculated energy balance or individual metabolites would alone (Moyes et al., 2013). This index was applied in the current study to identify potential biomarkers in liver for PI during lactation using proteomic profiling.

\section{Metabolic Profiles of PI in Early Lactation}

Before restriction, PI cows had higher plasma NEFA and lower glucose coupled with higher liver TAG and a tendency for lower glycogen content when compared 
Table 4. Significantly $(P \leq 0.05)$ up- or downregulated proteins before and during nutrient restriction for cows in mid lactation classified based on degree of physiological imbalance $(\mathrm{PI})^{1}$

\begin{tabular}{|c|c|c|c|}
\hline Accession number & Name & $\begin{array}{l}\text { Fold change }^{2} \\
\quad(\mathrm{PI} \text { vs. N) }\end{array}$ & Function \\
\hline \multicolumn{4}{|l|}{ Before restriction } \\
\hline ENSBTAP00000014894 & $\alpha$-actinin- 4 & 1.11 & Actin binding non-muscular cells \\
\hline ENSBTAP00000014649 & Prostaglandin reductase 1 & 1.10 & Inactivation of leukotriene B4 \\
\hline ENSBTAP00000000630 & Alcohol dehydrogenase [NADP +$]$ & 1.07 & Ketone biosynthesis \\
\hline ENSBTAP00000043063 & Hemoglobin subunit $\beta$ & -1.11 & Oxygen transport \\
\hline \multicolumn{4}{|l|}{ During restriction } \\
\hline UniProt ID: Q0IIL6 & Hydroxysteroid (17- $\beta$ ) dehydrogenase 4 & 1.20 & Steroidogenesis \\
\hline ENSBTAP00000024335 & Acetyl-Coenzyme A acyltransferase 1 & 1.14 & Ketone biosynthesis \\
\hline ENSBTAP00000005472 & Acyl-Coenzyme A oxidase 2 & 1.14 & Fatty acid oxidation, peroxisomes \\
\hline ENSBTAP00000020272 & Epoxide hydrolase 2 & 1.12 & Drug detoxification \\
\hline ENSBTAP00000012523 & Acyl-CoA-binding protein & 1.10 & $\beta$-oxidation of fatty acids \\
\hline UniProt ID: Q3SZX4 & Carbonic anhydrase 3 & -1.19 & Antioxidant defense \\
\hline ENSBTAP00000001947 & Ornithine carbamoyltransferase & -1.10 & Urea cycle \\
\hline ENSBTAP00000019719 & Annexin A6 & -1.10 & Ras/MAPK inactivation \\
\hline UniProt ID: Q2KJC5 & Hydroxyacyl-Coenzyme A dehydrogenase & -1.07 & NADH production \\
\hline ENSBTAP00000009844 & Short-chain specific acyl-CoA dehydrogenase & -1.05 & $\beta$-oxidation of fatty acids \\
\hline
\end{tabular}

${ }^{1}$ The PI index was generated from a subset of 6 Holstein cows where PI index $=\ln [\mathrm{NEFA}]_{\text {plasma }}+\ln [\text { BHBA }]_{\text {plasma }}-[\text { glucose }]_{\text {plasma. }}$ For each cow, the PI index was calculated based on averages before nutrient restriction. The top 3 cows classified as having the least (normal, $\mathrm{N}$; $\mathrm{n}=3$ ) or greatest (PI; $\mathrm{n}=3$ ) degree of PI were used.

${ }^{2}$ Fold-change difference in expression of liver proteins for cows classified as PI versus N.

with $\mathrm{N}$ cows. The lack of differences in concentrations of plasma and milk BHBA before restriction between $\mathrm{PI}$ and $\mathrm{N}$ cows indicated that the conversion of acetylCoA to ketone bodies was minimal. However, due to the overall higher liver TAG content observed, the capacity for complete hepatic $\beta$-oxidation of NEFA was insufficient and a significant proportion of NEFA were re-esterified and stored as TAG in the liver for PI compared with $\mathrm{N}$ cows. Although plasma BHBA concentration did not differ between groups before restriction, our results further support the use of an index to characterize a cow's metabolic status that reflects changes in blood as well as liver profiles during early lactation (Moyes et al., 2013).

Milk yield was not different between PI and N cows throughout the study period, regardless of the stage of lactation, suggesting that degree of PI is independent of milk yield. Calculated energy balance was lower overall for PI compared with $\mathrm{N}$ cows and indicates that degree of energy balance is related to degree of PI during early lactation. During nutrient restriction to experimentally increase PI, the PI cows tended to cope with a dietary challenge via increased plasma NEFA and BHBA compared with $\mathrm{N}$ cows.
In ruminants, glucose is largely spared from being used as a carbon source for milk fatty acid synthesis because of the near absence of citrate lyase activity in the cytoplasm of mammary epithelial cells, which converts citrate to acetyl-CoA and oxaloacetate (OAA; Forsberg et al., 1984). For cows in early lactation, plasma NEFA were similar between groups during the restriction period, whereas milk fat remained elevated for PI compared with $\mathrm{N}$ cows, indicating that plasma BHBA may have served as the primary source of carbons for de novo milk fat synthesis in the mammary gland for PI cows during nutrient restriction. A similar theory may also hold true for PI cows in mid lactation, where milk fat and BHBA were higher, whereas no changes in plasma NEFA were observed throughout the study period compared with $\mathrm{N}$ cows.

\section{Metabolic Profiles of PI in Mid Lactation}

Before restriction, metabolic profiles in blood and liver were similar between PI and N cows. Overall, PI cows had higher total plasma protein and milk fat, BHBA, and protein contents, with a tendency for higher milk citric acid content coupled with a tendency 
for lower liver glucose content compared with $\mathrm{N}$ cows. The lack of clear differences in plasma BHBA between groups may indicate increased uptake of plasma BHBA into the mammary gland to supply carbons for de novo TAG synthesis; this may partly explain the increased milk BHBA and fat content for PI compared with $\mathrm{N}$ cows. Throughout the study period, PI and N cows responded similarly in regard to all other changes in milk, blood, and liver parameters.

Cows categorized as PI or $\mathrm{N}$ during the pre-restriction period represent a state of naturally occurring PI (i.e., primary PI) that occurs more frequently during early lactation (Ingvartsen, 2006), whereas secondary PI most likely occurs later in lactation as a consequence of pre-existing health problems that reduce feed intake (i.e., "off-feed" situations; Vazquez-Añon et al., 1994; Ingvartsen and Andersen, 2000; Moyes et al., 2013). The iTRAQ-based proteomic profiling confirms the hypothesis that different coping strategies are observed between PI and N cows when subjected to a metabolic challenge or "off-feed" situation in mid lactation and identifies potential mechanisms associated with the development of PI and risk of disease during lactation.

\section{Potential Biomarkers for PI in Early Lactation}

Different proteins were isolated for cows in early and mid lactation, which may be partly attributed to the low sample size ( $\mathrm{n}=3$ /group) and thus, the identification of potential biomarkers for PI would be separate for cows in early and mid lactation.

Before restriction, PI resulted in the upregulation of $\mathrm{PC}$ (EC 6.4.1.1), which catalyzes the irreversible conversion of pyruvate to form OAA. Oxaloacetate is a precursor for the tricarboxylic acid cycle as well as gluconeogenesis via the conversion of OAA to phosphoenolpyruvate (PEP). The upregulation of $\mathrm{PC}$ may be supported by the upregulation of VLCAD (EC 1.3.99.13), an enzyme involved in the hepatic $\beta$-oxidation of long-chain fatty acids. The end product of hepatic oxidation of NEFA is acetyl-CoA, which is an activator of $\mathrm{PC}$ and may lead to increased mitochondrial supply of OAA (Chow and Jesse, 1992). Our results suggest an increased demand for energy via a potential increase in precursors for the tricarboxylic acid cycle and gluconeogenesis for PI compared with $\mathrm{N}$ cows in early lactation.

Of the 3 enzymes downregulated by PI during early lactation-ICDHm (EC 1.1.1.42), GLYAT (EC 2.3.1.13), and UGDH (EC 1.1.1.22) - all are involved in the detoxification of xenobiotics or antioxidant defense. However, ICDHm is also involved in energy metabolism associated with the tricarboxylic acid cycle where it participates in converting isocitrate to $\alpha$-ketoglutarate via oxidative decarboxylation and provides NADH for antioxidant systems (Jo et al., 2001). Coupled with an upregulation of enzymes related to fatty acid metabolism and gluconeogenesis, the potential decreased ability of the liver to control antioxidants increases risk of liver damage for PI cows in early lactation and may be a potential mechanism linking PI to increased risk of disease during early lactation. However, this relationship warrants verification from studies with larger sample sizes.

During nutrient restriction to experimentally increase PI, risk of liver damage was exacerbated for PI compared with $\mathrm{N}$ cows via the increased expression of enzymes associated with the $\beta$-oxidation of long-chain fatty acids [i.e., MTP- $\alpha$ (EC 4.2.1.7) and ECH (EC 4.2.1.17)], gluconeogenesis, and the tricarboxylic acid cycle (i.e., PC), and a downregulation of enzymes involved in antioxidant defense [i.e., GSTM-1 (EC 2.5.1.18), MnSOD (EC 1.15.1.1), GLYAT, and AOX (EC 1.2.3.1)], fatty acid binding (i.e., L-FABP), and apoptosis (i.e., 14-3-3 protein $\beta / \alpha$ ). Coupled with the upregulation of $\mathrm{PC}$, our results indicate a marked increase in the oxidation of fatty acids for energy for cows in PI, suggesting that the capacity for complete hepatic $\beta$-oxidation of NEFA was insufficient, and leading to increased accumulation of liver TAG for PI cows.

The upregulation of MTP- $\alpha, \mathrm{PC}$, and ECH (involved in fatty acid oxidation) may partly explain the higher overall liver TAG for PI compared with N cows in early lactation. The liver's ability to control the increased oxidation of fatty acids may have been impaired for PI cows via the downregulation of (1) L-FABP to control transport of fatty acids, (2) 4 proteins involved in antioxidant defense (i.e., GSTM-1, MnSOD, GLYAT, and AOX) and (3) 14-3-3 protein $\beta / \alpha$. The altered expression of these proteins indicates impaired fatty acid transport and control of the normal redox state, which may lead to increased liver cell damage, reduced hepatic capacity to control fatty acid oxidation, and increased risk of fatty liver disease. This is supported by results of Hardwick et al. (2010), in which antioxidant defense enzymes, such as GSTM-1, were impaired as nonalcoholic fatty liver disease progressed in human patients. These results lay a foundation for future studies focused on the relationship between fatty acid oxidation and antioxidant defense that may link PI and risk of diseases during early lactation, such as fatty liver and ketosis.

\section{Potential Biomarkers for PI in Mid Lactation}

Before nutrition restriction, ADH-4 (EC 1.1.1.1) and $\mathrm{ADH}[\mathrm{NADP}+]$ (EC 1.1.1.2) were upregulated by PI, indicating an increase in ketone biosynthesis. Methylmalonate-semialdehyde is an intermediate step involved 
in valine degradation, producing propionyl-CoA, and an upregulation of MMSDH may indicate a drive for increased use of AA as carbon sources for gluconeogenesis (Wiltrout and Satter, 1972).

Dihydrolipoamide dehydrogenase (DLD; EC 1.8.1.4) is the third component of pyruvate, $\alpha$-ketoglutarate, and branched-chain AA-dehydrogenase complexes (Babady et al., 2007; Van Brummelen and du Toit, 2007). The upregulation of DLD provides further support for the potential increased energy demand and utilization of amino acids in the tricarboxylic acid cycle for PI compared with $\mathrm{N}$ cows and provides a new avenue for future studies examining the relationship between AA metabolism and the development of PI during lactation.

Similar to cows in early lactation, in mid-lactation cows, nutrient restriction resulted in an overall upregulation of proteins associated with fatty acid oxidation for PI compared with $\mathrm{N}$ cows, whereas proteins downregulated were primarily involved in antioxidant defense. Similar to protein expression before nutrient restriction, proteins upregulated by nutrient restriction were involved in ketone biosynthesis. Acetyl-CoA acetyltransferase (Thl-2; EC 2.3.1.9) is a biosynthetic thiolase, which converts 2 units of acetyl-CoA to acetoacetyl $\mathrm{CoA}$ and is involved in ketone synthesis, such as BHBA (Stim-Herndon et al., 1995). The overall upregulation of liver proteins involved in ketone biosynthesis (1) indicates that hepatic expression of proteins involved in the ketogenesis pathway was not sufficient to alter plasma BHBA concentrations, or (2) provides support for the potential increased uptake of plasma BHBA into the mammary gland for milk TAG synthesis for PI cows.

The cytosolic protein ACBP was also upregulated by nutrient restriction for PI compared with $\mathrm{N}$ cows in mid lactation. The upregulation of ACBP suggests a potential surplus of acyl-CoA in the liver for $\mathrm{PI}$ compared with $\mathrm{N}$ cows during nutrient restriction. This is supported by the upregulation of CPT-2 (EC 2.3.1.7) and ACO-2 (EC 1.3.3.6), key enzymes involved in hepatic fatty acid $\beta$-oxidation in the mitochondria and peroxisomes, respectively (Hosomi et al., 2010). Nutrient restriction in lactating cows has been shown to increase peroxisomal $\beta$-oxidation of long-chain fatty acids ( $\geq$ C:20) and may help the liver cope with excess uptake of NEFA by providing an oxidative pathway (via ACO-2) that is independent of $\mathrm{CPT}$ regulation (Drackley et al., 2001). Coupled with an upregulation of CPT-2 and ACBP, the upregulation of ACO-2 may be a potential mechanism linked to the development of PI during early lactation.

Of the proteins downregulated by nutrient restriction for PI and N cows in mid lactation, PMSR (EC 1.8.4.6),
GSTA-1 (EC 2.5.1.18), and CAR-3 (EC 4.2.1.1) are primarily involved in antioxidant defense (Moskovitz, 2005; Giantin et al., 2010). Coupled with the downregulation of the metalloenzyme CAR-3, our results suggest impairment in the elimination of compounds produced during oxidative stress for PI compared with $\mathrm{N}$ cows, which may lead to increased cellular damage and premature death. Future investigation regarding the link to between oxidative stress and degree of PI is warranted.

\section{CONCLUSIONS}

This study is the first to (1) identify potential biomarkers in liver reflecting the degree of PI, based on plasma NEFA, BHBA, and glucose, and (2) provide new avenues for future large-scale studies focused on the specific mechanisms associated with the development of PI during lactation. Based on their relative importance and biological links to naturally occurring PI as well as for practical reasons (i.e., potential for analysis in milk using laboratory technology currently available), we identified PC and ICDHm as potential hepatic biomarkers for PI for cows during early lactation and ADH-4 and DLD as potential biomarkers for cows in mid lactation. However, because of the small sample size, future studies will be needed to verify the usefulness of the potential biomarkers as predictors of PI and thereby risk of disease that will help improve animal health and productivity during lactation.

\section{ACKNOWLEDGMENTS}

Funding from the Danish National Advanced Technology Foundation (Copenhagen, Denmark), Lattec I/S (Hillerød, Denmark), The Milk Levy Fund (Copenhagen, Denmark), and the Danish Ministry of Food, Agriculture and Fisheries (Copenhagen, Denmark) is acknowledged. Gratitude is extended to D. Thomassen (Department of Animal Science, Aarhus University, Tjele, Denmark) for her skillful help during analysis of samples.

\section{REFERENCES}

Babady, N. E., Y. P. Pang, O. Elpeleg, and G. Isaya. 2007. Cryptic proteolytic activity of dihydrolipoamide dehydrogenase. Proc. Natl. Acad. Sci. USA 104:6158-6163.

Bjerre-Harpøth, V., N. C. Friggens, V. M. Thorup, T. Larsen, B. M. Damgaard, K. L. Ingvartsen, and K. M. Moyes. 2012. Metabolic and production profiles of dairy cows in response to decreased nutrient density to increase physiological imbalance at different stages of lactation. J. Dairy Sci. 95:2362-2380.

Chong, P. K., C. S. Gan, T. K. Pham, and P. C. Wright. 2006. Isobaric tags for relative and absolute quantitation (iTRAQ) reproducibility: Implication of multiple injections. J. Proteome Res. 5:1232-1240. 
Chow, J. C., and B. W. Jesse. 1992. Interactions between gluconeogenesis and fatty acid oxidation in isolated sheep hepatocytes. J. Dairy Sci. 75:2142-2148.

Drackley, J. K., A. D. Beaulieu, and J. P. Elliott. 2001. Responses of milk fat composition to dietary fat or nonstructural carbohydrates in Holstein and Jersey cows. J. Dairy Sci. 84:1231-1237.

Forsberg, N. E., R. L. Baldwin, and N. E. Smith. 1984. Roles of acetate and its interactions with glucose and lactate in cow mammary tissue. J. Dairy Sci. 67:2247-2254.

Giantin, M., R. M. Lopparelli, V. Zancanella, P. G. Martin, A. Polizzi, G. Gallina, F. Gottardo, C. Montesissa, L. Ravarotto, T. Pineau, and M. Dacasto. 2010. Effects of illicit dexamethasone upon hepatic drug metabolizing enzymes and related transcription factors mRNAs and their potential use as biomarkers in cattle. J. Agric. Food Chem. 58:1342-1349.

Gygi, S. P., B. Rist, S. A. Gerber, F. Turecek, M. H. Gelb, and R. Aebersold. 1999. Quantitative analysis of complex protein mixtures using isotope-coded affinity tags. Nat. Biotechnol. 17:994-999.

Hardwick, R. N., C. D. Fisher, M. J. Canet, A. D. Lake, and N. J. Cherrington. 2010. Diversity in antioxidant response enzymes in progressive stages of human nonalcoholic fatty liver disease. Drug Metab. Dispos. 38:2293-2301.

Hosomi, R., K. Fukunaga, H. Arai, S. Kanda, T. Nishiyama, and M. Yoshida. 2010. Effect of dietary protamine on lipid metabolism in rats. Nutr. Res. Pract. 4:462-469.

Ingvartsen, K. L. 2006. Feeding- and management-related diseases in the transition cow, physiological adaptions around calving and strategies to reduce feeding-related diseases. Anim. Feed Sci. Technol. 126:175-213.

Ingvartsen, K. L., and J. B. Andersen. 2000. Integration of metabolism and intake regulation: A review focusing on periparturient animals. J. Dairy Sci. 83:1573-1597.

Ingvartsen, K. L., and K. M. Moyes. 2013. Nutrition, immune function and health of dairy cattle. Animal 7(Suppl. 1):112-122. 10.1017/ S175173111200170X.

Jo, S. H., M. K. Son, H. J. Koh, S. M. Lee, I. H. Song, Y. O. Kim, Y. S. Lee, K. S. Jeong, W. B. Kim, J. W. Park, B. J. Song, and T. L. Huh. 2001. Control of mitochondrial redox balance and cellular defense against oxidative damage by mitochondrial NADP+-dependent isocitrate dehydrogenase. J. Biol. Chem. 276:16168-16176.
Løvendahl, P., and H. M. Purup. 2002. Technical note: Time-resolved fluoro-immunometric assay for intact insulin in livestock species. J. Anim. Sci. 80:191-195.

Moskovitz, J. 2005. Methionine sulfoxide reductases: Ubiquitous enzymes involved in antioxidant defense, protein regulation, and prevention of aging-associated diseases. Biochim. Biophys. Acta 1703:213-219.

Moyes, K. M., T. Larsen, and K. L. Ingvartsen. 2013. Generation of an index for physiological imbalance and its use as a predictor of disease in dairy cows during early lactation. J. Dairy Sci. 96:2161-2170.

NRC. 2001. Nutrient Requirements of Dairy Cattle. National Academy Press, Washington, DC.

Ross, P. L., Y. N. Huang, J. N. Marchese, B. Williamson, K. Parker, S. Hattan, N. Khainovski, S. Pillai, S. Dey, S. Daniels, S. Purkayastha, P. Juhasz, S. Martin, M. Bartlet-Jones, F. He, A. Jacobson, and D. J. Pappin. 2004. Multiplexed protein quantitation in Saccharomyces cerevisiae using amine-reactive isobaric tagging reagents. Mol. Cell. Proteomics 3:1154-1169.

SAS Institute. 2008. SAS User's Guide: Statistics. Version 9, 2nd ed. SAS Institute Inc., Cary, NC.

Seifi, H. A., S. J. LeBlanc, K. E. Leslie, and T. F. Duffield. 2011. Metabolic predictors of post-partum disease and culling risk in dairy cattle. Vet. J. 188:216-220.

Song, X., J. Bandow, J. Sherman, J. D. Baker, P. W. Brown, M. T. McDowell, and M. P. Molloy. 2008. iTRAQ experimental design for plasma biomarker discovery. J. Proteome Res. 7:2952-2958.

Stim-Herndon, K. P., D. J. Petersen, and G. N. Bennett. 1995. Characterization of an acetyl-CoA C-acetyltransferase (thiolase) gene from Clostridium acetobutylicum ATCC 824. Gene 154:81-85.

Van Brummelen, R., and D. du Toit. 2007. L-Methionine as immune supportive supplement: A clinical evaluation. Amino Acids 33:157-163.

Vazquez-Añon, M., S. Bertics, M. Luck, R. R. Grummer, and J. Pinheiro. 1994. Peripartum liver triglyceride and plasma metabolites in dairy cows. J. Dairy Sci. 77:1521-1528.

Wiltrout, D. W., and L. D. Satter. 1972. Contribution of propionate to glucose synthesis in the lactating and nonlactating cow. J. Dairy Sci. 55:307-317. 